\title{
RESPONSABILIDAD SOCIAL MUNICIPAL BAJO LA PERCEPCIÓN DE LOS JÓVENES EN CIUDADES DE TURISMO DE NEGOCIOS Y RECREATIVO
}

\author{
Ruth del Castillo Romo ${ }^{1}$ \\ Celina López-Mateo ${ }^{2}$ \\ María Dolores Sánchez-Fernández ${ }^{3}$
}

\begin{abstract}
Resumen
El turismo, ya sea de negocios como recreativo, es un sector importante en México para el desarrollo de sus municipios, por ello, adoptar un enfoque desde la Responsabilidad Social Municipal (RSM) supone un factor importante para el desarrollo del municipio. Este artículo analiza la percepción de jóvenes residentes del municipio de Celaya; caracterizada por turismo de negocios, y Playa del Carmen; orientada al turismo recreativo, acerca de la RSM a través de las variables; Potencial, Desarrollo, Transparencia, Medio Ambiente, Edad y Municipio. Se estima un modelo econométrico de la RSM a través del método de Mínimos Cuadrados Ordinarios (MCO), donde se encuentran como determinantes el Potencial, Desarrollo, Transparencia y Medio Ambiente.
\end{abstract}

Palabras-clave; Responsabilidad social municipal; jóvenes; turismo

\begin{abstract}
Tourism, whether it is business or recreative, it is an important sector for the development of the municipalities in México, thats why the importance to adopt a focus since the Municipal Social Responsability (MSR) perspective for the development of the city. This work analyze the perception of Municipal Social Responsability through the variables; Potencial, Development, Transparency, Enviroment, Age and municipality, on residents youngs of the Celaya city, and Playa del Carmen. Where Celaya is characterized for received business tourism, and Playa del Carmen for recreative tourism. It is establish a econometric model of the MSR through the method of Ordinary Least Squares, where the Potential, Development, Transparency and Enviroment are founded as determinants.
\end{abstract}

Key-words; Municipal Social Responsability; youngs; tourism.

${ }^{1}$ Universidad de Guanajuato, Celaya, Guanajuato (México).E-mail:truth.delcastillo@gmail.com Orcid id: https://orcid.org/0000-0002-2017-1523

${ }^{2}$ Universidad de Guanajuato, Celaya, Guanajuato (México). E-mail:celinalm@gmail.com

Orcid id: https://orcid.org/0000-0003-4472-0416

${ }^{3}$ Universidade da Coruña, (Espanha). E-mail:msanchezf@udc.es Orcid id: https://orcid.org/0000-0001-9065-1699

Recebido em 25.01.2019

Aprovado em 20.10.2019

Revista Administração em Diálogo

ISSN 2178-0080

Programa de Estudos Pós-Graduados em Administração

Pontifícia Universidade Católica de São Paulo 


\section{Introducción}

La Responsabilidad Social(RS) o Responsabilidad Social Empresarial (RSE), emergida de las preocupaciones sociales y medioambientales da a lugar a acciones empresariales y de organismos(Bigne, Chumpitaz, Andreu y Swaen, 2005). Está integrada por 3 actores: gobierno, empresas y sociedad (Cano-Lara y Vélez-Romero, 2016) y vigilada por diversas instituciones que regulan y certifican con el fin de vigilar y controlar la RSE (López, Ojeda y Ríos, 2016).Así, el actor gobierno, también responde a una Responsabilidad Social, en este caso, Gubernamental (RSG) que es la capacidad de respuesta que tienen las instituciones gubernamentales hacia sus grupos de interés, a través del diseño y ejecución de políticas públicas (Cano-Lara y Vélez-Romero, 2016). La misma desencadena en la Responsabilidad Social Municipal (RSM), que está en función del bien común de la población (Sectur, 2003), la cual está conformada de acuerdo con el levantamiento de la Encuesta Intercensal 2015por un24\%de jóvenes entre 20 y 34 años de edad (INEGI, 2015).

En función de lo anterior, la RSM puede accionar la promoción turística de un municipio siendo el turismo, uno de los sectores que tiene mayor importancia en la economía nacional y regional (Sectur, 2003).En México en el 2016contribuyó con el 8.7\% del PIB nacional (INEGI, 2018), por lo cual su aprovechamiento e impulso depende de los incentivos o economías locales y micro-regionales (Moreno y Coromoto, 2010; Propin y Sánchez, 2007). Esta aportación tiene un efecto en la satisfacción y cambio en la calidad de vida de los residentes con la actividad turística del municipio (Castillo, Osuna y López, 2012). Así, para diseñar políticas públicas en beneficio del desarrollo turístico y del municipio, es importante conocer las percepciones y actitudes del residente (Gursoy, Jurowski y Uysal, 2002) pues éste es un actor importante en la responsabilidad social del municipio (Cano-Lara y VélezRomero, 2016). De ahí la importancia enanalizar la percepción que tienen los residentes de ciudades con distinto tipo de turismo. Por lo mismo a partir de 2004, las investigaciones que toman en cuenta la perspectiva del residente en el turismo han incrementado (Castillo, Osuna y López, 2012), encontrándose investigaciones acerca de la percepción específica que tienen los residentes del turismo y los turistas enPlaya del Carmen, Solidaridad (Mendoza y Leal, 2010).

El objetivo general de este trabajo es analizar los determinantes de la percepción que tienen los jóvenes acerca de la Responsabilidad Social de su Municipio, desde la perspectiva de una ciudad que ofrece turismo recreativo y otra de negocios.

El trabajo tiene la siguiente estructura: en la primera sección se presenta el marco teórico, posteriormente se encuentra la metodología, resultados y finalmente, las conclusiones.

\section{Marco Teórico}

\section{Responsabilidad social y su definición}

La responsabilidad social (RS)nace de las preocupaciones sociales y medioambientales, dando lugar a acciones empresariales y organismos que cuiden y satisfagan dichas preocupaciones (Barroso, 2013; Bigne et al., 2005; Secretaría de Economía, 2016). Por lo anterior, la RS también conocida como responsabilidad social empresarial (RSE) es vigilada por los gobiernos, investigadores y organismos con relación a sus tres ejes: social, económico y ambiental (Cajiga, 2018) surgiendo a nivel internacional diversas organizaciones donde crean normas y certificaciones con ánimo de vigilar, regular y promover la RS (López, Ojeda y Ríos, 2016). En México, la principal asociación en materia de RSE se crea en 1988, siendo elCentro Mexicano para la Filantropía (CEMEFI), miembro de la Alianza para la 
Responsabilidad Social Empresarial (AliaRSE), donde se agrupan Cámaras y Asociaciones empresariales con la finalidad de difundir y promover la responsabilidad y la sustentabilidad de las empresas a través de la obtención del distintivo Empresa Socialmente Responsable(Tamayo, 2016). Así,los organismos que integran AliaRSE coinciden y entienden la RSE como la formación del bien de la comunidad a través del cumplimiento de tres ejes señalados considerando las expectativas de los participantes (Cajiga, 2018).

\section{Principios y Ejes de la Responsabilidad Social en México}

Bajo los ejes anteriores, se desprenden los principios generados para el aseguramiento de una correcta implementación de la RS, estos son: Transparencia, Vinculación con la comunidad, Honestidad y legalidad, Justicia y Equidad, Empresarialidad y Desarrollo Socia 1(Cajiga, 2018). Mientras que el caso de la norma Internacional Organization for Standarization ISO 26000 no es certificable, pero contribuye y fomenta el desarrollo sostenible, aborda siete materias de responsabilidad social: derechos humanos, prácticas laborales, gobernabilidad, medio ambiente, prácticas justas de operación, asuntos de consumidores, participación activa y desarrollo de la comunidad (ISO, 2010).

Así, la RS también es definida como la integración de tres actores: gobierno, empresas y sociedad (Cano-Lara y Vélez-Romero, 2016) para mitigar la problemática de acuerdo con los ejes laboral, social, medioambiental y derechos humanos, a través de la transparencia de la relación y diálogo entre los stakeholders.

Dado lo anterior, es importante que los órganos del gobierno de las entidades del país analicen las necesidades de esos grupos para que puedan responder con valores y compromisos socialmente responsables (Deloitte, 2012), así como estar conscientes del impacto de las actividades que tienen sobre el medio ambiente, el ámbito social, alineando con el quehacer económico tanto en las empresas, como en alguna otra organización, ya sea gubernamental o religiosa. Es así que surgen otros tipos de RS, uno de ellos es la Responsabilidad Social Gubernamental RSG, que nace para mitigar los reclamos sociales y el desgaste ambiental, sin embargo la RSG no es muy reconocida como tal y pocos gobiernos participan de estas prácticas (Barroso, 2013), así su base recae en ser socialmente responsable, haciendo frente a las acciones que realiza con los que se relaciona, es decir con los ciudadanos (Cano-Lara y Vélez-Romero, 2016).Si bien la ISO 2600, deja en claro que sus normas no sustituyen a las políticas que el gobierno implementa para el desarrollo sustentable de la población (ISO, 2010), la norma establece un conjunto de pautas que pueden ser seguidas por el Estado en función de buscar el desarrollo sustentable (Camacho, 2015).

\section{Responsabilidad Social Gubernamental}

La Responsabilidad Social Gubernamental RSG, es la capacidad de respuesta que tienen las instituciones gubernamentales hacia sus grupos de interés, a través del diseño y ejecución de políticas públicas, de forma que su responsabilidad hacia las actividades de los ciudadanos, organizaciones y empresas es tanto externa como interna (Cano-Lara y Vélez-Romero, 2016).

Uno de los mayores problemas de la RSG en Latinoamérica es la transparencia hacia los ciudadanos. Los informes de las actividades gubernamentales deberían ser más abiertos y difundidos en diversos medios para que los ciudadanos puedan acceder a ellos, sean buenos o malos. Sin embargo, este punto de la transparencia ha sido el talón de Aquiles para las democracias y gobiernos latinoamericanos (Emmerich, 2004). De esta forma, la RSG no solo se da al exterior mediante el establecimiento, ejecución de acciones y normativas para las 
actividades de los individuos como de las empresas, sino que también obedecen a una responsabilidad interna dentro de su misma actividad y con las personas que forman parte de este organismo (Cano-Lara y Vélez-Romero, 2016), la RSG se aplica a los tres ámbitos: federal, estatal y municipal (Borthiry, 2002).

Es a nivel federal, donde el gobierno se encarga de realizar análisis externos acerca del movimiento turístico del país, determina objetivos para aumentar el turismo y define estrategias en conjunto con la entidad federativa, para poder alcanzar las metas(SECTUR, 2003). De esta forma, la Responsabilidad Social Estatal refiere al gobierno responsable para con sus ciudadanos, siendo su función el gestionar con acciones éticas, justas y sustentables que cubran sus necesidades y sean de beneficio para mejorar la calidad y nivel de vida tanto para la comunidad presente como para la del futuro (Morales, 2017).

Derivado de lo anterior, el municipio, al formar parte de la estrucutra del estado, busca su desarrollo y el de sus residentes, así como laResponsabilidad Social Municipal, trabaja para cuidar el bien común de la población (Camacho, 2015), a través de diversas acciones como mantener el orden, recaudar impuestos, llevar a cabo el mejoramiento de equipamiento e infraestructura, así como desarrollar y/o promover eventos culturales y cívicos, además del cuidado del medio ambiente, por lo cual el régimen municipal junto con una estrategia estatal puede accionar a la promoción turística del municipio practicando la responsabilidad social hacia sus habitantes (SECTUR, 2003).

Es indudable la importancia de la Responsabilidad Social en los tres ámbitos de gobierno, donde la percepción de los habitantes, en este caso jóvenes, es fundamental para que con base en ella, se realice una planeación estratégica y políticas públicas que favorezcan al desarrollo del municipio y sus mismos habitantes, por lo que este trabajo se centra en la Responsabilidad Social Municipal.

\section{Responsabilidad social municipal en ciudades de turísticas}

El municipio confluye en una localidad donde conviven los habitantes o ciudadanos bajo el constructo social, político-administrativo, ambiental y territorial siendo en el territorio donde se entrelazan las acciones del gobierno con la participación de los ciudadanos (Méndez y Ablan, 2012). De manera que un municipio que se encuentra en un territorio que cuenta con recursos naturales (entendiendo por naturales, tanto ubicación geográfica, como elementos de la naturaleza), cuturales o históricos, da paso a la geografía turística (Guzmán y Fernández, 1997). Así entonces, un municipio puede a través de sus actores sociales; gobierno, residentes y empresarios, debido a su participación, decidir si el muncipio se convierte en ciudad turística o no, lo cual si se decide serlo, implica contar o fomentar un modelo de desarrollo integral (SECTUR, 2003). Ya que ser un municipio turístico tiene implicaciones culturales para los residentes, pues el municipio debe ajustarse a las políticas a nivel nacional estatal y municipal en materia de turismo, por lo mismo, los residentes son quienes principalmente deben estar convencidos de la importancia que el turismo tiene para su ciudad (Frávega 1992 en Borthiry, 2002).Aunque, si bien el turismo en el municipio puede traer beneficios, también puede generar problemas, como contaminación, tráfico, uso excesivo de los recursos naturales.

La responsabilidad social del municipio, en acción de la promoción turística de un destino, recae en cumplir sus principales funciones las cuales son planificación de uso de suelo, servicios básicos y construcción de obra pública, regulación y control del desarrollo, recaudación de impuestos, coordinación y promoción del municipio turístico (SECTUR, 
2003), por lo que la gestión del municipio debe encaminar su progreso de manera planificada (SECTUR, 2003; FIIAPP, 2011;).

Con la finalidad de contribuir al desarrollo del territorio, el ordenamiento, y dotación de infraestructura acorde a las necesidades de la población y condiciones del crecimiento del municipio, se realiza la planificación del uso de suelo que se refiere al potencial que tiene el municipio con respecto a su naturaleza implícita, esto es el tipo de industria que tiene, zona donde se encuentra (SECTUR, 2003), no importando la particularidad del destino turístico, el crecimiento de su potencial natural depende del suministro de infraestructura por parte del sector público para tener la condición de atracción de los turistas (Mendoza y Leal, 2010).

Una imagen atractiva del destino está ligada a los servicios básicos y construcción de obra pública con la que el municipio cuenta y que éstos cubran las necesidades básicas de la población (educación, agua, centros de salud, vivienda, espacios recreativos, transporte, etc.) para poder incentivar con ello una iniciativa turística (SECTUR, 2003).

Esto se debe ejecutar con regulación y control del desarrollo, de acuerdo con las leyes orgánicas donde se establecen los planes de ordenación territorial, para planear adecuadamente el desarrollo del municipio y contar con las instalaciones necesarias, considerando la conservación del medio ambiente, pues una de las responsabilidades del municipio turístico es reducir los impactos sobre el medio ambiente, así como hacer partícipe a los ciudadanos en la conservación de recursos naturales, aunado a ello, el cuidado del patrimonio histórico y cultural con el que cuenta el municipio (SECTUR, 2003), por lo tanto, el desarrollo de la infraestructura para el turismo hace que se aproveche mayor el potencial turístico (SECTUR, 2014).

A través de la recaudación de impuestos, se realiza el financiamiento para asegurar la cobertura de los servicios básicos y la construcción de obra pública e infraestructura que necesita el municipio (SECTUR, 2003), donde los ciudadanos buscan transparencia del gasto público (FIIAPP, 2011).

El municipio, como responsable de mejorar la calidad de vida de la población, en coordinación con otros organismos públicos, así como con el sector privado (Bigne et al., 2005; Cano-Lara y Vélez-Romero, 2016), deben coordinarse para para incorporar proyectos que mejoren la vida social y cultural de la comunidad, y una vez coordinadas, poder acercarlas a través de campañas de promoción y publicidad, dando pie a una cultura turística (SECTUR, 2003), donde la participación social en conjunto de la comunidad o ciudadanos, las empresas y el municipio hacen posible el desarrollo turístico del municipio(Bigne et al., 2005; Cano-Laray Vélez-Romero, 2016; SECTUR, 2003) cambiando la relación entre turista y residente conforme va aumentando el número y tiempo de estancia de turistas en la ciudad, pues el encuentro también va en búsqueda de obtener una gananacia inmediata (Cohen, 1982). Por lo que, dada la importancia que tiene la participación social de los ciudadanos, debe notarse que la población predominante en México son los jóvenes (INAFED, 2017).

En la literatura encontrada, se observa que los jóvenes muestran una percepción neutral hacia la responsabilidad social, siendo que exponenuna mayor sensibilidad a la dimensión medioambiental, además de que se ha apreciado que los jóvenes de menos de 24 años son más desintereados en las prácticas de responsabilidad social, mientras que los jóvenes de 25 a 34 años donde aquellos que cuentan con más recursos económicos, tienden a realizar acciones a favor de organismos que son socialmente responsables (Monfort de Bedoya, 2011). Sin embargo, es importante que se tomen en cuenta a los jóvenes para observar el proceso de responsabilidad social del municipio (Bigne et al., 2005; Monfort de Bedoya, 2011; Hincapié, 2013), puesto que es fundamental considerar su perspectiva para las politicas públicas, lo 
cual, va en función de mejorar las condiciones de vida y el fortalecimiento de los gobiernos municipales (INAFED, 2017).

\section{Turismo en México y su importancia}

El turismo en México aporta en la derrama económica. En el 2016 contribuyó con el 8.7\% al PIB nacional (INEGI, 2018), por tanto, el consumo turístico, contribuye al PIB, teniendo una importancia para la economía del país (CEPAL, 2007).Así, para el primer trimestre del 2017, el PIB turístico fue de 113.1 millones de presos a precios de 2013, el cual se compone de: transporte de pasajeros; restaurantes, bares y centros nocturnos; alojamiento; agencias de viajes y otros servicios de reserva; bienes y artesanías; comercio; servicios culturales; servicios deportivos y recreativos entre otros (INEGI, 2018).

De acuerdo al Censo Económico 2014, el valor agregado censal bruto (VACB), es decir, el valor de la producción que involucra el proceso de trabajo por la actividad creadora, tanto de transformación del personal ocupado, como el capital y la organización, ejercida sobre los materiales que se consumen en la realización de la actividad económica, en este caso la actividad turística (SECTUR, 2016), el estado de Quintana Roo fue el estado con mayor a portaciónal VACB con 44.2\%, Guanajuato con 9.7\%, don la media nacional se ubicó con 7.1\% (SECTUR, 2016). Ver gráfica 1.

Gráfica 1. Participación del Valor Agregado Censal Bruto turístico por entidad federativa

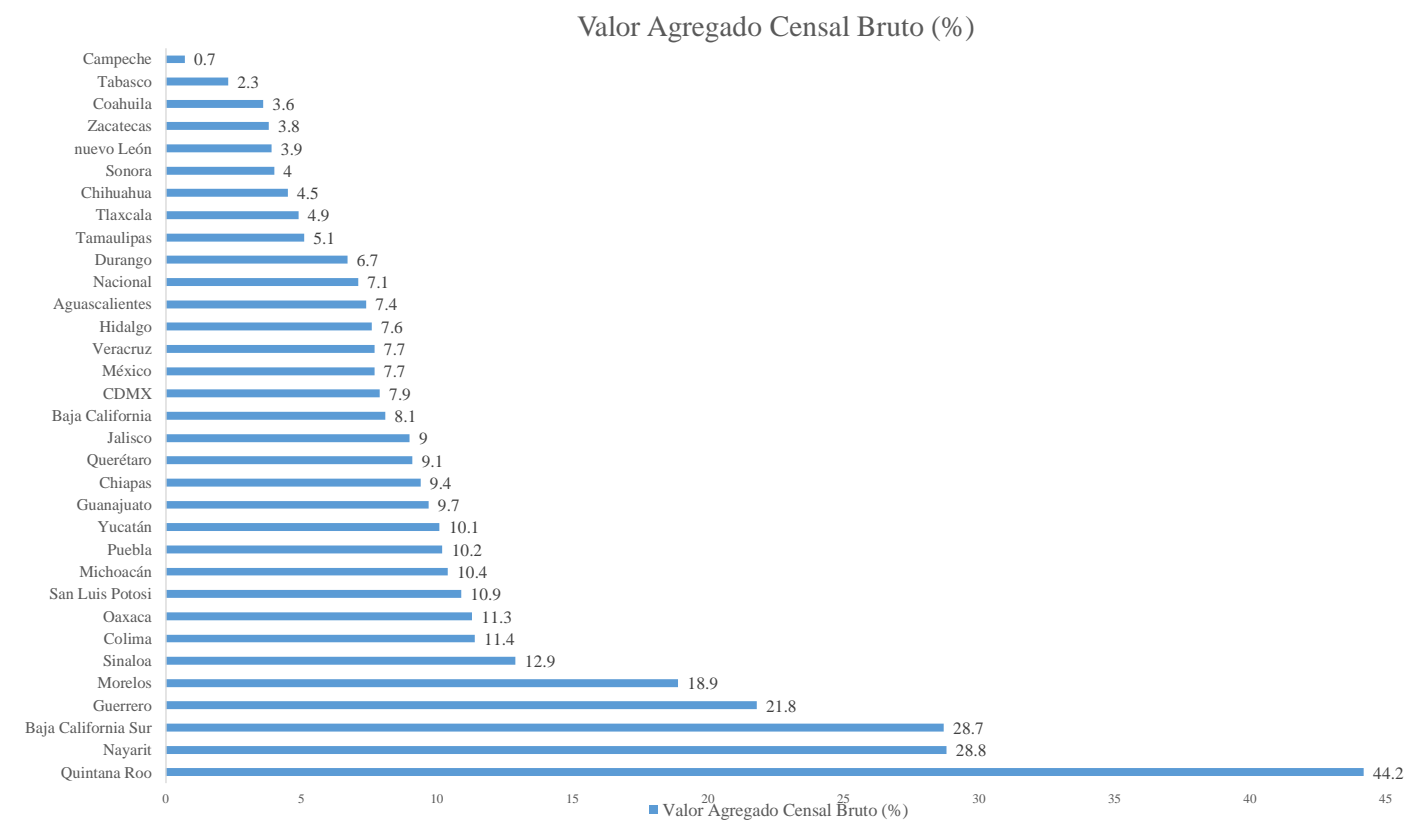

Fuente. INEGI, 2014 en SECTUR (2016)

En cuanto al número de Unidades Económicas que tiene cada estado, de acuerdo con el Censo Económico de 2014, Quintana Roo cuenta con 23.1\% UE enfocadas al turismo, mientras que Guanajuato ocupa $14.5 \%$ de las unidades a este sector, lo cual los ubica en el primer y octavo lugar a nivel nacional, respectivamente (INEGI, 2014 en SECTUR, 2016). 


\section{Turismo de Negocios y Recreativo}

El turismo por lo tanto, es definido como un fenómeno social, cultural y económico, derivado de las actividades que realizan las personas cuando salen de viaje o realizan estancias distintas de su entorno habitual en el periodo de un año. Cabe mencionar que un viajero, es un visitante que viaja ya sea por cuestiones de negocios o motivos personales, por lo que su viaje no implica otra actividad adicional a ella, convirtiéndose en turista cuando pernocta en la ciudad destino (UNTWO, 2018).

Las clasificaciones de turismo varían, aunque existe una clasificación general que desprende dos categorías de turismo, una que es por motivos personales y otra por negocios, así, el turismo que se realiza por motivos personales, pueden ser por vacaciones, recreo y ocio, educación, salud, religión, compras y otros, mientras que la que es por motivos de negocios y/o profesionales, involucra el desarrollo de reuniones, convenciones y ferias(Naciones Unidas, 2008; SECTUR, 2003, 2018; UNWTO, 2018;).También el Atlas Turístico de México de SECTUR, clasifica al turismo en cultural, de reuniones, deportivo, de salud y bienestar, sol y playa, naturaleza, gastronómico y otras alternativas (SECTUR, 2018), mientras que en el Plan de Desarrollo Turístico 2013-2018 de México, se considera a los tipos de turismo de sol y playa, cultural, de negocios, ecoturismo yaventura, de salud, deportivo y de lujo (SECTUR, 2013).

De acuerdo con INEGI (2018), con datos de las Cuentas Satélite de Turismo de 2016 de cuatro países (México, Perú, Malasia y Nueva Zelanda) los motivos de viaje por negocios representaron el 5.9\% en el 2016, y los motivos de vacaciones o recreo fue de $36.7 \%$ (Gráfica 2).

Gráfica 2. Consumo de turismo por motivos de viaje en el $2016(\%)$

$$
\text { Consumo por motivo de viaje (\%) }
$$

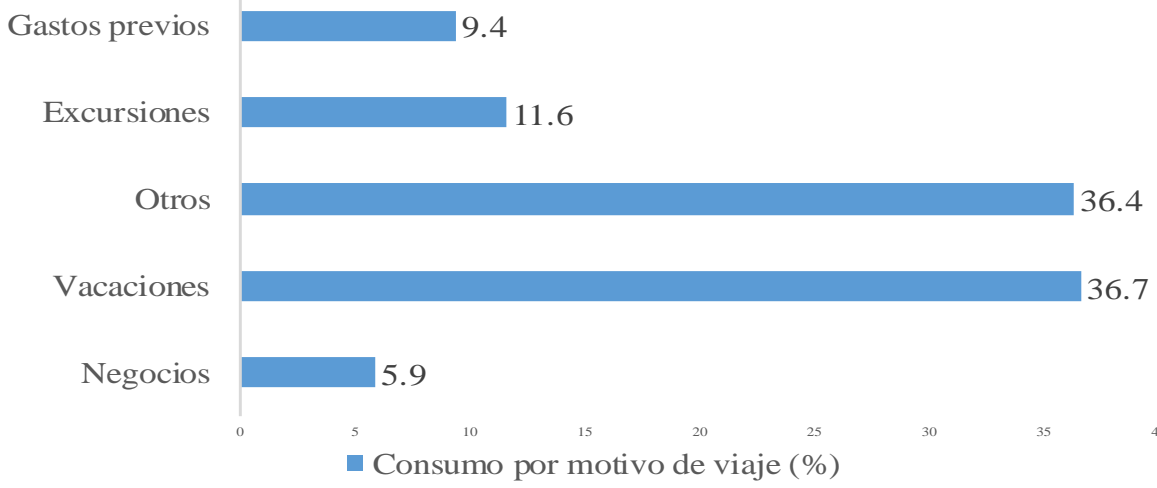

Fuente. INEGI (2018).

Es así entonces, que el turismo de negocios en México también contribuye al PIB, siendo que en el 2017 la derrama económica que contribuyó a nivel nacional fue de 1.5 por ciento del PIB nacional, donde además se estima que un turista de reuniones llega a gastar hasta seis veces más que un turista de recreo y ocio que va a sol y playa (SECTUR, 2018). De manera, que al turismo de negocios, se considera también así a los viajes o destinos que se ofertan por cuestiones económicas y laborales para los viajes de ejecutivos empresarios o servidores públicos así como viajes con relación al comercio (Vidal, 2004 en Moreno y 
Coromoto, 2011).El beneficio de este turismo no solo es económico, pues también beneficia a las comunidades locales, importan conocimiento y se abren programas de responsabiildad social, lo cual atrae la inversión para mejorar el destino turístico (SECTUR, 2018).

Ejemplo de ello, es que debido al crecimiento de la industria automotriz en el estado de Guanajuato perteneciente a la Región Bajío, el turismo de negocios llegó a ocupar en 2016 el segundo el lugar en la actividad económica más importante del estado, pasando de 8.4 a 9.1 puntos porcentuales dentro del PIB estatal en el periodo 2013- 2015 (Romo, 2016). Así, Celaya, municipio de dicho estado, posee una ubicación privilegiada en el centro del país, siendo el cruce de rutas comerciales (Celaya, 2015). De manera que el turismo de negocios en Celaya representó el $80 \%$ de la actividad turística, ofertando alrededor de 2 mil 300 habitaciones (Zárate, 2015), donde para el 2016, Celaya ocupó el sexto lugar en México por su facilidad de hacer negocios (CONCANACO, 2017).

Continuando con el turismo de sol y playa, éste se caracteriza por ofrecer descanso y esparcimiento, por lo mismo, abarca actividades turísticas de ocio y recreativas que se desarrollan en el lugar, incluyendo el desarrollo y oferta de servicios de hospitalidad, alimentos, vivienda como segunda casa o lugar de descanso, así como actividades acuáticas propias de la zona (Bigné, Sánchez y Currás, 2008).

Es así entonces, que dado que el principal contribuyente al PIB turístico nacional es Quintana Roo (SECTUR, 2016), donde el destino con mayor demanda turística del estado es la Riviera Maya, la cual está comprendida por Akumal, Boca Paila, Cobá, Cancún, Cozumel, Puerto Morelos, Punta Allen, Solidaridad y Tulum (H. Ayuntamiento de Solidaridad, 2016 en Castillo-Pavón y Méndez-Ramírez, 2017). Siendo la cabecera del municipio de Solidaridad, Playa del Carmen o "Playa" como la llaman los quintanarroenses, misma que está ubicada como paso obligado para aquellos que quieren viajar a Cozumel, donde además de ser un destino de sol y playa, parte del turismo gira en torno a la quinta avenida, calle cosmopolita que ofrece una amplia variedad de servicios turísticos (Xacur, 2001), además de ser la ciudad central de la Riviera Maya. Las actividades que ofrece la Riviera Maya son de recreación, donde hay parques temáticos y eventos como el Festival de Jazz, Festival de Vida y Muerte de Xcaret, entre otros (SECTUR, 2013), por lo que se referirá en este estudio a Playa, como un municipio de turismo recreativo.

De manera que dada la importancia que tiene el turismo de negocios y el turismo recreativo, siendo este último como principal tipo de turismo que se realiza por motivos personales, se enfoca este trabajo en ciudades que reciben a estos turistas.

\section{Los jóvenes en ciudades de turismo de negocios y recreativo}

Entendiendo que la conformación de los municipios, se realiza con la participación de los ciudadanos, se observa que el grupo que constituyen gran parte de la población del país se concentra en los jóvenes, los cuales también forman parte de una gran fuerza laboral (INAFED, 2017; OIT, 2017).En cuanto al término joven, si bien no hay un claro consenso de las edades que comprenden a esta población, la Organización Internacional del Trabajo OIT (OIT, 2015, 2013; OIT-Américas, 2017) así como el Centro de Información de las Naciones Unidas (2018) componen sus estudios con la información obtenida de los jóvenes, que comprenden de15 a 19 años de edad, y considerando como jóvenes adultos a aquellos que oscilan entre 20 y 24 años, (Sánchez, 2014), de la misma forma en México el Consejo Nacional de Población (CONAPO), presenta como jóvenes a aquellos que tienen entre 15 y 24 años (CONAPO, 2000). Por otro lado, la Unión Europea los engloba como a aquellos que tienen entre15 y 29 años. Para Sánchez (2014), dentro de una población joven, se realizan 
distintas categorías como son adolescentes de 12 a 15 años, jóvenes de 16 a 24 años y adultos jóvenes de 25 a 34 años. Así, como los autores Monfort de Bedoya (2011), Ochoa (2016) y Salgado (2018), incluyen a los jóvenes como aquellos que están entre 15 a 34 años de edad. Por lo tanto, para esta investigación se considera trabajar con dos grupos de edad; de 18 a 24 años y 25 a 34 años de edad.

Conforme a lo anterior, se pone en contexto que Celaya al 2015, el $22 \%$ de la población corresponde a la ocupación por los jóvenes, teniendo el $9 \%$ una edad entre 20 y 24 años, $8 \%$ entre 25 y 29 años, mientras que el $7 \%$ corresponde a los que presentaban una edad de 30 a 34 años (INEGI, 2015).

En el caso de Playa del Carmen, municipio que recibe turismo recreativo, de acuerdo con el censo de población levantado por INEGI en 2010, la densidad poblacional en Solidaridad es de 149,923 habitantes concentrándose en las edades de 20 a 34 años (SECTUR, 2013), y para el 2015 la población pasó a 209,634 habitantes, correspondiendo el 12\% a jóvenes de 18 a 24 años, $12 \%$ de 25 a 29 años, y $11 \%$ a los que tienen de 30 a 34 años de edad (INEGI, 2015).

\section{Metodología}

El tipo de investigación utilizada fue de carácter exploratorio, siendo el levantamiento realizado en los meses de enero a marzo del 2018. La aplicación del instrumento se hizo de manera individual cara a cara, en diferentes entornos tanto de Playa del Carmen como de Celaya (Tabla 1). La medición de cada ítem está en base escala Likert de 1 a 5 , donde 1 equivale a totalmente en desacuerdo, hasta 5, como totalmente de acuerdo. La fiabilidad de dicho instrumento, de acuerdo a los 10indicadores mencionados en la operacionalización de variables, se expone en la Tabla 2. Este instrumento presenta un Alfa de Cronbach de 0.832, lo cual es un nivel confiable (Sáenz y Tamez, 2014). Una vez recolectada la información, los datos fueron tabulados primero en Excel para un análisis posterior en el software SPSS 23.

Tabla 1 Ficha técnica

\begin{tabular}{ll}
\hline Método de levantamiento & Cara a Cara \\
\hline Periodo de levantamiento & Enero- Marzo 2018 \\
\hline Universo de Estudio & $\begin{array}{l}\text { Jóvenes (18 a 34 años) del municipio de Playa } \\
\text { del Carmen y Celaya. }\end{array}$ \\
\hline Tamaño de muestra & $\begin{array}{l}60 \text { jóvenes (30 de Celaya y 30 de Playa del } \\
\text { Carmen) }\end{array}$ \\
\hline Selección de muestra & Sistemática por cuota \\
\hline
\end{tabular}

Técnica de análisis estadístico Tablas de contingencia y correlacional

\begin{tabular}{ll}
\hline \multirow{2}{*}{ Instrumento } & Elaborado por Sánchez-Fernández y Ríos- \\
& Manríquez (2019)
\end{tabular}

Fuente. Elaboración propia 
Tabla 2. Operacionalización de variables

Fuente. Elaboración propia con base al instrumento elaborado por Sánchez-Fernández y RíosManríquez (2019).

\begin{tabular}{|c|c|c|}
\hline VARIABLE & ITEM & CÓ́DIGO \\
\hline \multirow{2}{*}{ Potencial } & El municipio tiene una imagen atractiva. & P1 \\
\hline & Mi municipio realiza fiestas, ferias, etc. & $\mathrm{P} 2$ \\
\hline \multirow{2}{*}{ Desarrollo } & $\begin{array}{l}\text { Considero que el gobierno municipal es transparente en los procesos } \\
\text { de ejecución de los recursos a todos los programas en beneficio de } \\
\text { los ciudadanos. }\end{array}$ & DES 22 \\
\hline & $\begin{array}{l}\text { Creo que el municipio donde vivo fomenta la formación y el } \\
\text { desarrollo profesional de sus grupos de interés (vecinos, trabajadores, } \\
\text { etc.) }\end{array}$ & DES 3 \\
\hline \multirow{2}{*}{ Transparencia } & $\begin{array}{l}\text { Considero que el gobierno municipal es transparente en el manejo de } \\
\text { los recursos. }\end{array}$ & TR 21 \\
\hline & $\begin{array}{l}\text { El Gobierno municipal divulga a la ciudadanía de los ingresos y } \\
\text { gastos que ejerce el municipio. }\end{array}$ & TR 15 \\
\hline \multirow{3}{*}{ Medio Ambiente } & $\begin{array}{l}\text { Se utilizan fuentes de energía alternativas en mi municipio (como } \\
\text { celdas solares, etc.). }\end{array}$ & MA 16 \\
\hline & $\begin{array}{l}\text { El gobierno municipal planifica sus inversiones para reducir el } \\
\text { impacto medioambiental. }\end{array}$ & MA 17 \\
\hline & $\begin{array}{l}\text { Se utiliza, compra o favorece la producción de artículos ecológicos } \\
\text { en mi municipio. }\end{array}$ & MA 19 \\
\hline $\begin{array}{l}\text { Responsabilidad } \\
\text { Social Municipal }\end{array}$ & En términos generales mi municipio es socialmente responsable. & RSM \\
\hline
\end{tabular}

Como parte de la metodología se analizó la información con tablas de contingencia, seguido de un análisis de correlación para después realizar un análisis de regresión que ayude a explicar la percepción de los jóvenes hacia la responsabilidad social del municipio, con lo cual se determina el siguiente modelo de regresión múltiple:

$$
\mathrm{RSM}=\beta_{0}+\beta_{1} P O T_{1 i}+\beta_{2} D E S_{2 i}+\beta_{3} T R_{3 i}+\beta_{4} M A_{4 i}+\beta_{5} E D_{5 i}+\beta_{6} M N_{6 i}+\varepsilon_{i}
$$

Donde, $\mathrm{RSM}=$ percepción de la responsabilidad social del municipio, $\mathrm{POT}=$ Potencial del municipio, DES= Desarrollo de los ciudadanos, TR= Transparencia en el manejo de recursos, $\mathrm{MA}=$ Medio Ambiente, $\mathrm{ED}=\mathrm{Edad}, \mathrm{MN}=$ Municipio turístico, $\varepsilon_{i}$ es el término de error aleatorio.

Por lo tanto, para responder al objetivo de la investigación se plantean las siguientes hipótesis:

$\mathrm{H}_{1}$ :Existen diferencias en la percepción de los jóvenes que reciben turismo de negocios acerca de la RS del municipio con los jóvenes que reciben turismo recreativo.

$\mathrm{H}_{2:}$ La transparencia en la ejecución de los recursos del municipio, influye positivamente en la percepción que tienen los jóvenes acerca de la responsabilidad social del municipiodonde residen. 
$\mathrm{H}_{3}$ :Los recursos del municipio en función del desarrollo de los habitantes, influye de manera favorable en la percepción que tienen los jóvenes acerca de la responsabilidad social del municipio donde residen.

$\mathrm{H}_{4}$ :Las acciones que fomenta el municipio para el cuidado del medio ambiente, se relacionan positivamente con la percepción que tienen los jóvenes acerca de la responsabilidad social del municipio donde residen.

$\mathrm{H}_{5}$ :La imagen atractiva del municipio como parte de su potencial, está relacionada de manera positiva con la percepción que tienen los jóvenes acerca de la responsabilidad social del municipio donde residen.

\section{Análisis de Resultados}

Se realizó un análisis de Alfa de Cronbach para medir la fiabilidad del instrumento, en cada una de las dimensiones, obteniendo en conjunto de las 5 variables un Alpha de Cronbach de 0.756 , lo que confirma nuevamente la viabilidad del instrumento, detallando el análisis de fiabilidad por dimensión en la Tabla 3. Dado que la variable edad y municipio son sociodemográficas no se incluyen en esta medición.

Tabla 3. Análisis de fiabilidad de Alfa de Cronbach

\begin{tabular}{cccccc}
\hline \hline & POT & DES & TR & MA & RSM \\
\hline \hline $\begin{array}{c}\text { Valor de Alpha de Cronbach } \\
\text { No. Items }\end{array}$ & 0.727 & 0.648 & 0.706 & 0.852 & N.A \\
\cline { 2 - 6 } & 2 & 2 & 2 & 3 & 1 \\
\hline \hline
\end{tabular}

Nota. N.A. = no aplica

Fuente. Cálculos propios

Para el análisis específico por municipio se realizaron tablas de contingencia, las cuales se pueden apreciar más delante de acuerdo al tipo de turismo del municipio (ver Tablas 4 y 5 ).

\section{Celaya, municipio de turismo de negocios}

Para los jóvenes de 18 a 34 años de edad, el $40 \%$ están en desacuerdo en que el municipio de Celaya cuente con una imagen atractiva. Para el 17\% los jóvenes de 18 a 24 años y un $40 \%$ de los que tienen 25 a 34 años están de acuerdo con que el municipio realiza fiestas y ferias. En cuanto al Desarrollo de los ciudadanos, sólo el 3\% de los dos grupos de jóvenes perciben que el gobierno es transparente en la ejecución de los recursos destinados a los programas en beneficio de los ciudadanos, así, un 30\% de los jóvenes expresan desconocimiento o indiferencia acerca de que el municipio fomenta la formación y desarrollo profesional de sus grupos de interés.

En cuanto a la Transparencia del gobierno, el $70 \%$ de los jóvenes perciben que el gobierno del municipio no es transparente en el manejo de los recursos, siendo más notorio por los que tienen 25 a 34 años. Lo mismo sucede con la percepción de la divulgación de información de ingresos y egresos hacia los ciudadanos.

Mientras que el cuidado del Medio Ambiente, es destacable para los tres ítems que componen la dimensión, pues la percepción de los jóvenes está orientada hacia la falta de actividades del municipio para el cuidado del medio ambiente, pues el $60 \%$ indica que no se utilizan fuentes de energías alternativas, un $83 \%$ manifiesta que no se invierte en acciones para la reducción de impacto ambiental, y un $77 \%$ expresa que no se utiliza, compra o se favorece la producción de artículos ecológicos en el municipio. Como consecuencia de ello, el $33 \%$ de los jóvenes no distinguen si el municipio es socialmente responsable, comparado con 
el $63 \%$ que señalan que Celaya no es un municipio socialmente responsable, siendo más enfatizado en un $47 \%$ por el grupo de 25 a 34 años, lo anterior se puede contrastar en la Tabla 4.

Tabla 4.Tabla de contingencia de percepción hacia la RSM de Celaya (\%)

\begin{tabular}{|c|c|c|c|c|c|c|c|c|c|}
\hline & & Celaya & & & & & & & \\
\hline VARIABLE & ITEM & CódIGO & EDAD & T.DES & M.D & N.D.N.A & M.AC & T.AC & Total \\
\hline \multirow{6}{*}{$\begin{array}{l}\frac{\pi}{0} \\
\frac{\pi}{0} \\
0 \\
0\end{array}$} & \multirow{3}{*}{ El municipio tiene una imagen atractiva. } & \multirow{3}{*}{ P1 } & $18-24$ & 10 & 3 & 13 & 7 & 3 & 37 \\
\hline & & & $25-34$ & 13 & 13 & 20 & 13 & 3 & 63 \\
\hline & & & Total & 23 & 17 & 33 & 20 & 7 & 100 \\
\hline & \multirow{3}{*}{ Mi municipio realiza fiestas, ferias, etc. } & \multirow{3}{*}{ P2 } & $18-24$ & 3 & 3 & 13 & 10 & 7 & 37 \\
\hline & & & $25-34$ & 0 & 10 & 13 & 23 & 17 & 63 \\
\hline & & & Total & 3 & 13 & 27 & 33 & 23 & 100 \\
\hline \multirow{6}{*}{ 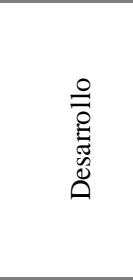 } & \multirow{3}{*}{$\begin{array}{l}\text { transparente en los procesos de ejecución } \\
\text { de los recursos a todos los programas en }\end{array}$} & \multirow{3}{*}{ DES 22} & $18-24$ & 7 & 10 & 17 & 3 & 0 & 37 \\
\hline & & & $25-34$ & 37 & 17 & 7 & 3 & 0 & 63 \\
\hline & & & Total & 43 & 27 & 23 & 7 & 0 & 100 \\
\hline & \multirow{3}{*}{$\begin{array}{l}\text { la formación y el desarrollo profesional de } \\
\text { sus grupos de interés (vecinos, }\end{array}$} & \multirow{3}{*}{ DES 3} & $18-24$ & 0 & 10 & 10 & 17 & 0 & 37 \\
\hline & & & $25-34$ & 17 & 20 & 20 & 7 & 0 & 63 \\
\hline & & & Total & 17 & 30 & 30 & 23 & 0 & 100 \\
\hline \multirow{6}{*}{ 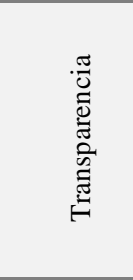 } & \multirow{3}{*}{$\begin{array}{l}\text { Considero que el gobierno municipal es } \\
\text { transparente en el manejo de los recursos. }\end{array}$} & \multirow{3}{*}{ TR 21} & $18-24$ & 13 & 7 & 17 & 0 & 0 & 37 \\
\hline & & & $25-34$ & 47 & 3 & 10 & 0 & 3 & 63 \\
\hline & & & Total & 60 & 10 & 27 & 0 & 3 & 100 \\
\hline & \multirow{3}{*}{$\begin{array}{c}\text { El Gobierno municipal divulga a la } \\
\text { ciudadanía de los ingresos y gastos que } \\
\text { ejerce el municipio. }\end{array}$} & \multirow{3}{*}{ TR 15} & $18-24$ & 7 & 13 & 13 & 3 & 0 & 37 \\
\hline & & & $25-34$ & 33 & 13 & 7 & 0 & 10 & 63 \\
\hline & & & Total & 40 & 27 & 20 & 3 & 10 & 100 \\
\hline \multirow{9}{*}{ 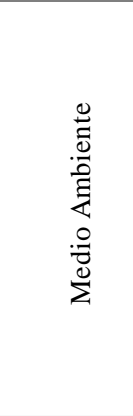 } & \multirow{3}{*}{$\begin{array}{l}\text { Se utilizan fuentes de energía alternativas } \\
\text { en mi municipio (como celdas solares, } \\
\text { etc.). }\end{array}$} & \multirow{3}{*}{ MA 16} & $18-24$ & 17 & 7 & 10 & 3 & 0 & 37 \\
\hline & & & $25-34$ & 17 & 20 & 23 & 3 & 0 & 63 \\
\hline & & & Total & 33 & 27 & 33 & 7 & 0 & 100 \\
\hline & \multirow{3}{*}{$\begin{array}{c}\text { El gobierno municipal planifica sus } \\
\text { inversiones para reducir el impacto } \\
\text { medioambiental. }\end{array}$} & \multirow{3}{*}{ MA 17} & $18-24$ & 20 & 7 & 7 & 3 & 0 & 37 \\
\hline & & & $25-34$ & 23 & 33 & 3 & 3 & 0 & 63 \\
\hline & & & Total & 43 & 40 & 10 & 7 & 0 & 100 \\
\hline & \multirow{3}{*}{$\begin{array}{c}\text { Se utiliza, compra o favorece la } \\
\text { producción de artículos ecológicos en mi } \\
\text { municipio. }\end{array}$} & \multirow{3}{*}{ MA 19} & $18-24$ & 13 & 10 & 13 & 0 & 0 & 37 \\
\hline & & & $25-34$ & 23 & 30 & 10 & 0 & 0 & 63 \\
\hline & & & Total & 37 & 40 & 23 & 0 & 0 & 100 \\
\hline \multirow{3}{*}{$\sum_{\substack{n \\
\simeq}}$} & \multirow{3}{*}{$\begin{array}{l}\text { En términos generales mi municipio es } \\
\text { socialmente responsable. }\end{array}$} & \multirow{3}{*}{ RSM } & $18-24$ & 13 & 3 & 17 & 3 & 0 & 37 \\
\hline & & & 25-34 & 27 & 20 & 17 & 0 & 0 & 63 \\
\hline & & & Total & 40 & 23 & 33 & 3 & 0 & 100 \\
\hline
\end{tabular}

Nota. T.DES $=$ Totalmente en desacuerdo, M.D.= Moderadamente en desacuerdo, N.D.N.A=Ni en desacuerdo ni de acuerdo, M.AC $=$ Moderadamente de acuerdo, $\mathrm{T} . \mathrm{AC}=$ Totalmente de acuerdo.

Fuente. Cálculos propios

\section{Playa del Carmen, municipio de turismo recreativo}

Durante el periodo de levantamiento de la información, el 57\% considera que Playa del Carmen, Solidaridad, tiene una imagen atractiva. Por otro lado, las acciones del gobierno hacia el desarrollo de sus ciudadanos no son percibidos por el $67 \%$ los jóvenes, enfatizándose más por los que tienen de 18 a 24 años de edad, lo que ocurre de manera similar en el caso de transparencia del manejo de recursos, ya que el $73 \%$ no está de acuerdo con que el municipio sea transparente. En cuanto al cuidado del medio ambiente, los jóvenes de 18 a 24 años de 
edad, son los que muestran una mayor despreocupación o desatención acerca de las acciones del municipio para el cuidado del medio ambiente. Derivado de lo anterior, el $47 \%$ de jóvenes incluyendo a los dos grupos de edades, perciben que el municipio de Playa del Carmen no es socialmente responsable, sin embargo, también un $47 \%$ indica una indiferencia acerca de ello, pues no están ni en acuerdo, ni en desacuerdo. Lo anterior puede observarse en la Tabla 5.

Tabla 5.Tabla de contingencia de percepción hacia la RSM de Playa Del Carmen (\%)

\begin{tabular}{|c|c|c|c|c|c|c|c|c|c|}
\hline \multicolumn{10}{|c|}{ Playa del Carmen } \\
\hline VARIABLE & ITEM & CÓDIGO & EDAD & T.DES & M.D & N.D.N.A & M.AC & T.AC & Total \\
\hline \multirow{6}{*}{$\begin{array}{l}\frac{\pi}{0} \\
\frac{\pi}{0} \\
0 \\
0\end{array}$} & \multirow{3}{*}{ El municipio tiene una imagen atractiva. } & \multirow{3}{*}{$\mathrm{P} 1$} & $18-24$ & 3 & 7 & 23 & 13 & 13 & 60 \\
\hline & & & $25-34$ & 3 & 0 & 7 & 17 & 13 & 40 \\
\hline & & & Total & 7 & 7 & 30 & 30 & 27 & 100 \\
\hline & \multirow{3}{*}{ Mi municipio realiza fiestas, ferias, etc. } & \multirow{3}{*}{$\mathrm{P} 2$} & $18-24$ & 0 & 3 & 17 & 17 & 23 & 60 \\
\hline & & & $25-34$ & 0 & 0 & 0 & 20 & 20 & 40 \\
\hline & & & Total & 0 & 3 & 17 & 37 & 43 & 100 \\
\hline \multirow{6}{*}{ 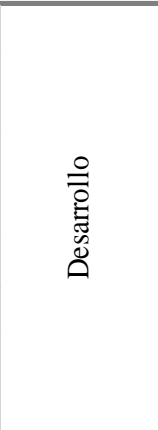 } & \multirow{3}{*}{$\begin{array}{l}\text { Considero que el gobierno municipal es } \\
\text { transparente en los procesos de } \\
\text { ejecución de los recursos a todos los } \\
\text { programas en beneficio de los } \\
\text { ciudadanos. }\end{array}$} & \multirow{3}{*}{ DES 22} & $18-24$ & 30 & 7 & 17 & 3 & 3 & 60 \\
\hline & & & $25-34$ & 27 & 3 & 10 & 0 & 0 & 40 \\
\hline & & & Total & 57 & 10 & 27 & 3 & 3 & 100 \\
\hline & \multirow{3}{*}{$\begin{array}{l}\text { Creo que el municipio donde vivo } \\
\text { fomenta la formación y el desarrollo } \\
\text { profesional de sus grupos de interés } \\
\text { (vecinos, trabajadores, etc.) }\end{array}$} & \multirow{3}{*}{ DES 3} & $18-24$ & 3 & 7 & 20 & 20 & 10 & 60 \\
\hline & & & $25-34$ & 10 & 17 & 10 & 3 & 0 & 40 \\
\hline & & & Total & 13 & 23 & 30 & 23 & 10 & 100 \\
\hline \multirow{6}{*}{ 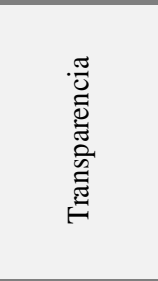 } & \multirow{3}{*}{$\begin{array}{c}\text { Considero que el gobierno municipal es } \\
\text { transparente en el manejo de los } \\
\text { recursos. }\end{array}$} & \multirow{3}{*}{ TR 21} & $18-24$ & 33 & 10 & 10 & 0 & 7 & 60 \\
\hline & & & $25-34$ & 30 & 0 & 10 & 0 & 0 & 40 \\
\hline & & & Total & 63 & 10 & 20 & 0 & 7 & 100 \\
\hline & \multirow{3}{*}{$\begin{array}{c}\text { El Gobierno municipal divulga a la } \\
\text { ciudadanía de los ingresos y gastos que } \\
\text { ejerce el municipio. }\end{array}$} & \multirow{3}{*}{ TR 15} & $18-24$ & 27 & 17 & 13 & 0 & 3 & 60 \\
\hline & & & $25-34$ & 20 & 10 & 3 & 0 & 7 & 40 \\
\hline & & & Total & 47 & 27 & 17 & 0 & 10 & 100 \\
\hline \multirow{9}{*}{ 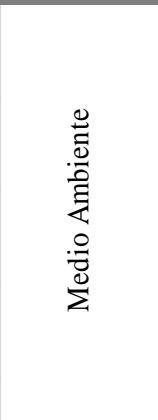 } & \multirow{3}{*}{$\begin{array}{l}\text { Se utilizan fuentes de energía } \\
\text { alternativas en mi municipio (como } \\
\text { celdas solares, etc.). }\end{array}$} & \multirow{3}{*}{ MA 16} & $18-24$ & 7 & 10 & 27 & 10 & 7 & 60 \\
\hline & & & $25-34$ & 20 & 7 & 13 & 0 & 0 & 40 \\
\hline & & & Total & 27 & 17 & 40 & 10 & 7 & 100 \\
\hline & \multirow{3}{*}{$\begin{array}{c}\text { El gobierno municipal planifica sus } \\
\text { inversiones para reducir el impacto } \\
\text { medioambiental. }\end{array}$} & \multirow{3}{*}{ MA 17} & $18-24$ & 10 & 7 & 27 & 17 & 0 & 60 \\
\hline & & & $25-34$ & 17 & 13 & 10 & 0 & 0 & 40 \\
\hline & & & Total & 27 & 20 & 37 & 17 & 0 & 100 \\
\hline & \multirow{3}{*}{$\begin{array}{c}\text { Se utiliza, compra o favorece la } \\
\text { producción de artículos ecológicos en mi } \\
\text { municipio. }\end{array}$} & \multirow{3}{*}{ MA 19} & $18-24$ & 13 & 3 & 23 & 17 & 3 & 60 \\
\hline & & & $25-34$ & 13 & 3 & 17 & 7 & 0 & 40 \\
\hline & & & Total & 27 & 7 & 40 & 23 & 3 & 100 \\
\hline \multirow{3}{*}{ 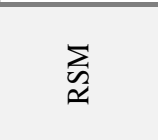 } & \multirow{3}{*}{$\begin{array}{l}\text { En términos generales mi municipio es } \\
\text { socialmente responsable. }\end{array}$} & \multirow{3}{*}{ RSM } & $18-24$ & 23 & 3 & 27 & 3 & 3 & 60 \\
\hline & & & $25-34$ & 17 & 3 & 20 & 0 & 0 & 40 \\
\hline & & & Total & 40 & 7 & 47 & 3 & 3 & 100 \\
\hline
\end{tabular}

Nota. T.DES $=$ Totalmente en desacuerdo, M.D.= Moderadamente en desacuerdo, N.D.N.A=Ni en desacuerdo ni de acuerdo, M.AC $=$ Moderadamente de acuerdo, T.AC $=$ Totalmente de acuerdo.

Fuente. Cálculos propios 


\section{Comparativa}

Al comparar las tablas 4 y 5, se observa que en cuanto al potencial del municipio reflejado en la oferta de programas de eventos, el $80 \%$ considera que Playa del Carmen, municipio de turismo recreativo sí realiza dichos eventos, mientras que en Celaya sólo el 56\% está de acuerdo en que se llevan a cabo. En cuanto al desarrollo de los ciudadanos en ambos municipios se percibe un gobierno donde los recursos no son destinados para el desarrollo de sus grupos de interés, de igual manera, no se percibe que el gobierno sea transparente en tanto en los recursos que ingresan y egresan, así como en el manejo de los mismos. En cuanto al cuidado del medio ambiente, se denota que los jóvenes de Celaya donde, se recibe a un turismo de negocios, existe menos fomento del municipio para el cuidado del medio ambiente con respecto a lo que se realiza en Playa del Carmen.

Sin embargo, cabe mencionar, que hay un mayor porcentaje de jóvenes que muestran menor interés en las acciones del gobierno municipal hacia el cuidado del medio ambiente de dicha ciudad comparado con los de Celaya. Por lo tanto, la percepción de los residentes de ambas ciudades, es la misma respecto a la responsabilidad social del municipio, mostrando mayor desinterés los jóvenes de Playa del Carmen con respecto a los de Celaya.

\section{Análisis de correlación}

Así, a través del análisis de correlación, se determina el grado de asociación entre los indicadores y variables, para la interpretación de los resultados de los coeficientes donde $r=1$ es una relación perfecta; mayor que 0.80, es una relación muy fuerte, entre 0.80 y 0.60 indica relación fuerte, siendo 0.60 y 0.40 una relación moderada, mientras que los resultados entre 0.40 y 0.20 es una relación baja, así entre 0.20 y 0 es muy baja, por lo tanto si se presenta un valor 0, se toma como una nula relación (Sáenz y Tamez, 2014).

Para dilucidar más los resultados obtenidos en la correlación por variables, se realizó la correlación entre los ítems que comprenden a las variables, observando que la percepción hacia la responsabilidad del municipio tiene una fuerte relación positiva y significativa de 0.613 con la ejecución de los recursos en beneficio de los ciudadanos (DES 22), siendo que con la Transparencia (TR 21) en cuanto al manejo de los recursos del municipio muestra una relación moderada de 0.529 , seguida con el mismo tipo de relación con la promoción del consumo de productos ecológicos (MA.19) por parte del municipio con 0.439 , mientras que conserva su relación moderada con el potencial del municipio con 0.425 respecto a la realización de fiestas y ferias (POT 2), por tanto, todas las anteriores guardan una relación positiva y significativa con la percepción de la responsabilidad del municipio (ver Tabla 6).

Es interesante destacar que la edad (ED) y el tipo de municipio (MN) no muestra una relación positiva ni significativa con la RSM, por lo tanto, no hay una asociación con la edad de los jóvenes de 18 a 24, ni 25 a 34 años, al igual que por el tipo de turismo que recibe la ciudad, con su percepción hacia la RSM, dado que sus valores son (-)0.181 para el ítem de edad, y (-)0.113 para el municipio. Cabe destacar que la Transparencia en el manejo de los recursos por parte del municipio (TR 21), tiene una muy fuerte relación significativa de 0.895 con la ejecución de los recursos para el beneficio de los ciudadanos (DES 22). Una relación moderada negativa y significativa (-0.501)es la edad (ED) con su opinión acerca de que elmunicipio donde vive fomenta la formación y el desarrollo profesional de sus grupos de interés (DES 3). 
Tabla 6.Correlación de indicadores

\begin{tabular}{|c|c|c|c|c|c|c|c|c|c|c|c|c|}
\hline CÓDIGO & RSM & POT 1 & POT 2 & DES 22 & DES 3 & TR21 & TR15 & MA16 & MA 17 & MA 19 & MN & ED \\
\hline $\mathrm{RSM}$ & 1 & & & & & & & & & & & \\
\hline POT 1 & $.379^{* *}$ & 1 & & & & & & & & & & \\
\hline POT 2 & $.425^{* *}$ & $.585^{* *}$ & 1 & & & & & & & & & \\
\hline DES 22 & $.613^{* *}$ & 0.176 & 0.148 & 1 & & & & & & & & \\
\hline DES 3 & $.370^{* * *}$ & $.334^{* *}$ & 0.171 & $.481^{* *}$ & 1 & & & & & & & \\
\hline TR21 & $.529^{* *}$ & 0.181 & 0.156 & $.895^{* *}$ & $.398^{* *}$ & 1 & & & & & & \\
\hline TR15 & $.326^{*}$ & 0.243 & $.413^{* *}$ & $.464^{* *}$ & 0.228 & $.549^{* *}$ & 1 & & & & & \\
\hline MA16 & 0.246 & -0.04 & 0.121 & 0.22 & 0.187 & 0.242 & -0.02 & 1 & & & & \\
\hline MA 17 & $.399^{* *}$ & 0.114 & 0.238 & $.466^{* *}$ & $.303^{*}$ & $.405^{* *}$ & 0.071 & $.731^{* *}$ & 1 & & & \\
\hline MA 19 & $.432^{* *}$ & $.282^{*}$ & 0.239 & $.468^{* *}$ & $.372^{* *}$ & $.428^{* * *}$ & 0.056 & $.528^{* *}$ & $.727^{* *}$ & 1 & & \\
\hline MN & -0.113 & $-.368^{* *}$ & $-.297^{*}$ & 0.032 & -0.149 & 0 & 0.066 & -0.183 & $-.311^{*}$ & $-.385^{* *}$ & 1 & \\
\hline ED & -0.181 & -0.004 & 0.135 & $-.284^{*}$ & $-.501^{* *}$ & -0.202 & -0.015 & $-.255^{*}$ & $-.315^{*}$ & -0.24 & 0.233 & 1 \\
\hline
\end{tabular}

Nota. La correlación es significativa al nivel 0,05 (bilateral) 5\% ** La correlación es significativa al nivel 0,01 (bilateral) $1 \%$

Fuente:Cálculos propios

Dado los valores anteriores obtenidos, se presenta la tabla de correlación entre las dimensiones generadas, donde se observa una relación positiva y significativa entre la percepción de la variable dependiente de responsabilidad social del municipio (RSM)con el desarrollo de los ciudadanos (DES), siendo ésta una relación moderada $(r=0.562)$, sin embargo, la percepción de la RSM, también se relaciona positiva y significativamente con el potencial, la transparencia y cuidado del medio ambiente, mostrando nuevamente que el factor edad y tipo de municipio turístico no muestra una relación positiva y significativa, como se observa en la Tabla 7. 
Tabla 7. Matriz de correlación de variables

\begin{tabular}{l|lccccccc}
\hline DIMENSION & CODIGO & RSM & POT & DES & TR & M. A. & ED & MN \\
\hline \hline $\begin{array}{l}\text { Percepción hacia la } \\
\text { responsabilidad } \\
\text { social del municipio }\end{array}$ & RSM & 1 & & & & \\
$\begin{array}{l}\text { Potencial del } \\
\text { municipio }\end{array}$ & POT & $.412^{* *}$ & 1 & & & & \\
$\begin{array}{l}\text { Desarrollo de los } \\
\text { ciudadanos }\end{array}$ & DES & $.562^{* *}$ & 0.241 & 1 & & & \\
$\begin{array}{l}\text { Transparencia del } \\
\text { gobierno }\end{array}$ & TR & $.514^{* *}$ & $.269^{*}$ & $.599^{* *}$ & & 1 & & \\
$\begin{array}{l}\text { Programas de } \\
\text { cuidado al medio } \\
\text { ambiente }\end{array}$ & M.A. & $.409^{* *}$ & 0.205 & $.362^{* *}$ & 0.235 & 1 & & \\
$\begin{array}{l}\text { Edad } \\
\text { Municipio del } \\
\text { residente }\end{array}$ & ED & -0.181 & 0.108 & $-.432^{* *}$ & -0.14 & $-.260^{*}$ & 1 & 1 \\
\hline
\end{tabular}

Nota. La correlación es significativa al nivel 0,05 (bilateral) 5\% ** La correlación es significativa al nivel 0,01 (bilateral) $1 \%$

Fuente. Cálculos propios.

\section{Análisis de regresión lineal}

El modelo de regresión lineal se estima por el método de Mínimos Cuadrados Ordinarios (MCO) con datos de corte transversal. La normalidad de los residuos se realiza a través de la prueba de Kolgomorov-Smirnov (K-S), encontrándose una distribución normal.

Se observa que las variables explicativas que influyen positiva y significativamente sobre la percepción hacia la Responsabilidad Social del Municipio con un nivel de confianza del $95 \%$ son Potencial y Desarrollo de los habitantes, mientras que las variables Transparencia del manejo de recursos y cuidado del Medio Ambiente, son relevantes para el modelo, ambas con un nivel de confianza del $90 \%$. Por último, las variables explicativas que no tienen una influencia sobre la variable dependiente son la Edad y el Municipio turístico donde residen los jóvenes. De manera conjunta, a un nivel de confianza del $99 \%$ se establece que las variables independientes ayudan a explicar el modelo de percepción de Responsabilidad Social del Municipio.

El modelo tiene una capacidad explicativa del $46.37 \%$ viéndose a partir del coeficiente de determinación ajustado. Así mismo, al ser un modelo basado en datos de corte transversal se verificó que no hubiera problemas de heterocedasticidad a través de la prueba BreuschPagan. En tanto, que la prueba de Ramsey se utilizó para detectar que no hubiera errores de especificación y/o variables omitidas en el modelo (Wooldridge, 2010). Los resultados del modelo se presentan en la Tabla 8. 
Tabla 8. Indicadores Mínimos Cuadrados Ordinarios MCO. Factores de Influencia en la Percepción de los jóvenes hacia la Responsabilidad Social Municipal

\begin{tabular}{|c|c|c|c|}
\hline $\begin{array}{c}\text { Factores de } \\
\text { Influencia } \\
\end{array}$ & Modelo & Estadís ticos & P-Valor \\
\hline Potencial & $2.13 * *$ & $\mathrm{R}^{2}$ ajustado & 0.46 \\
\hline Desarrollo & $2.03 * *$ & $\mathrm{~F}$ & 7.64 \\
\hline Transparencia & $1.69 *$ & Prob $>F$ & 0.00 \\
\hline Medio ambiente & $1.83 *$ & $\mathrm{~K}-\mathrm{S}$ & 0.08 \\
\hline Edad & -0.02 & Prob $>Z$ & 0.20 \\
\hline Municipio & 0.27 & Breusch-Pagan & 2.35 \\
\hline Constante & -1.01 & Prob $>X^{2}$ & 0.13 \\
\hline \multirow[t]{2}{*}{ Observaciones } & \multirow[t]{2}{*}{60} & $\begin{array}{c}\text { Prueba de } \\
\text { Ramsey }\end{array}$ & 1.04 \\
\hline & & Prob $>$ F & 0.43 \\
\hline
\end{tabular}

Nota. $* * *$ Nivel de significativa de los estimadores 0,01 (bilateral) $99 \%, * * 0,05$ (bilateral) $95 \%, * 0,1$ (bilateral) $90 \%$

Fuente. Cálculos propios

Dado que el modelo es de regresión múltiple, se realizan pruebas para detectar problemas de multicolinealidad, donde el valor del Factor de Tolerancia debe aproximarse a 1 y el Factor de Inflación de Varianza (FIV) debe ser menor a 10 (Gujarati, 2004). Debido a que los resultados obtenidos cumplen con los requisitos de las pruebas antes mencionadas, se concluye que el modelo no presenta multicolinealidad (Tabla 9).

Tabla9. Pruebas de multicolinealidad

\begin{tabular}{lcc}
\hline \hline Variable explicativa & $\begin{array}{c}\text { Factor de } \\
\text { Tole rancia }\end{array}$ & FIV \\
\hline \hline Potencial & 0.745 & 1.343 \\
\hline Desarrollo & 0.473 & 2.115 \\
\hline Transparencia & 0.604 & 1.657 \\
\hline Medio Ambiente & 0.771 & 1.298 \\
\hline Edad & 0.673 & 1.485 \\
\hline Municipio & 0.745 & 1.342 \\
\hline
\end{tabular}

Fuente. Cálculos propios. 


\section{Conclusiones y Discusión}

Así las ciudades de Celaya y Playa del Carmen, presentan una similitud, la cual radica en su ubicación geográfica, Celaya al centro del país, con ubicación estratégica para la conectividad con las zonas industriales y de negocios (Celaya, 2015), y Playa del Carmen perteneciente a la Riviera Maya, quese encuentra en un punto medio que conecta hacia Cancún,Cozumel y Tulum (Xacur, 2001).

Dado que el modelo propuesto para explicar la percepción de los jóvenes acerca de la Responsabilidad Social del Municipio turístico se explica con las variables independientes, se concluye que la variable dependiente depende de manera relevante del Potencial, Desarrollo, Transparencia y cuidado del Medio Ambiente del municipio.

Siguiendo entonces, con respuesta a las hipótesis que dieron inicio a esta investigación, se encuentra que la percepción de los jóvenes residentes de una ciudad que recibe turismo de negocios y recreativo, coinciden en que el municipio no es socialmente responsable, por tanto, la hipótesis 1 es rechazada, puesto que no existen diferencias.

Continuando con las hipótesis, la transparencia en la ejecución de los recursos del municipio, se asocia positivamente en la percepción que tienen los jóvenes acerca de la responsabilidad social del municipio donde residen, resultando la hipótesis 2 aceptada. En cuanto a la hipótesis 3 , dado los resultados de la regresión, se puede inferir que los recursos del municipio en función del desarrollo de los habitantes, influyen de manera positiva en la explicación hacia la percepción que tienen los jóvenes acerca de la responsabilidad social del municipio donde residen, siendo entonces la hipótesis aceptada.

En cuanto a las acciones que fomenta el municipio para el cuidado del medio ambiente, estas muestran una relación positiva hacia percepción que tienen los jóvenes acerca de la RSM del municipio donde viven, por lo que la hipótesis 4 no es rechazada. Así, la última hipótesis también se valida favorablemente, ya que una imagen atractiva del municipio forma parte de su potencial del municipio, pues está relacionada favorablemente hacia la percepción que tienen los jóvenes acerca de la responsabilidad social del municipio turístico donde viven.

Aunque en Celaya se presenta una oferta cultural (Sistema de Arte y Cultura Celaya, 2018), ésta no es percibida por los jóvenes de 18 a 24 años, por lo que esta información podría ser de utilidad para políticas públicas donde se incentive programas o eventos enfocados a este grupo de jóvenes.

Otras limitaciones radica en quedado que Playa del Carmen presenta un crecimiento del 2010 al 2015, del 40\% la población, (INEGI, 2018) pudiendo derivarse de un alto nivel de migración, tal como Castillo-Pavón y Méndez-Ramírez (2017) y Mendoza y Leal (2010) lo mencionan en sus investigaciones, pudiendo influir en la percepción dado que no son nativos de dicho municipio, por lo que sería importante como futura línea de investigación, analizar sus implicaciones hacia el desarrollo del municipio, que de acuerdo al Organismo Mundial de Turismo OMT (2018), la migración tiene implicaciones sociales y económicas impulsando la demanda turística.

También se observan resultados, de la importancia en la percepción de RSM, principalmente de la transparencia del gobierno en cuanto al uso de recursos y desarrollo para sus grupos de interés, (Emmerich, 2004). Es importante en la RSM el factor del medio ambiente, factor desfavorecido por el municipio, percibido así por los jóvenes, y que para la responsabilidad social gubernamental del municipio es importante para el desarrollo del municipio (Barroso, 2013; Cano-Lara y Vélez-Romero, 2016; SECTUR, 2003), siendo que 
según Monfort de Bedoya (2011), para los jóvenes la dimensión medioambiental es un tema que si preocupa a los jóvenes.

Es importante destacar, que acorde a lo que Monfort de Bedoya (2011) y Bigne et al., (2005), establece, los jóvenes muestran una percepción neutral por las acciones de responsabilidad social de los organismos, por lo que conforme con este estudio también se encuentra que la edad y en este caso además el tipo de municipio turístico no influyen en la percepción, aunque si bien sirven para explicar el modelo, pues no determinan una inclinación hacia la percepción del municipio, sin embargo, tal como lo menciona Gursoy, Jurowski y Uysal (2002), la percepción de los ciudadanos es importante para el desarrollo de políticas públicas.

Con base a los resultados mostrados, se plantean futuras líneas de investigación orientadas a las acciones del municipio con respecto a la responsabilidad social y competitividad del municipio, adicional a ello, una limitación potencial del estudio fue el tamaño de muestra, lo cual genera una alternativa interesante para ampliar el estudio con la posibilidad de profundizar las variables del modelo probado considerando grupos de otras edades. Por lo que otra futura línea de investigación sería orientar un estudio de las acciones que realizan los jóvenes como parte de responsabilidad social y que coadyuvan a la participación social en el municipio.

\section{Referencias}

Barroso, F. (2013). Fortalecimiento de la Responsabilidad Social Gubernamental (RSG) del Gobierno del Estado de Campeche desde los conceptos y prácticas de la Responsabilidad Social Empresarial (RSE).

Bigne, E., Chumpitaz, R., Andreu, L., y Swaen, V., (2005). Percepción De La Responsabilidad Social Corporativa: Un Análisis Cross-Cultural. Universia Business Review, $5,14-27$.

Bigné, E., Sánchez, I., Currás, R. (2007). El papel de la imagen del destino en la valoración y comportamiento postcompra del turista de sol y playa. Papers de Turisme. 42, 57-73. Recuperado de http://www.papersdeturisme.gva.es/ojs/index.php/Papers/article/view/57/52

Borthiry, N. (2002). Gestión Pública Municipal del Turismo. Recuperado de http://nulan.mdp.edu.ar/1115/1/borthiry_n.pdf

Cajiga, J., (2018). El Concepto de Responsabilidad Social Empresarial. Recuperado de https://www.cemefi.org/esr/images/stories/pdf/esr/concepto_esr.pdf

Cano-Lara, E., y Vélez-Romero, X., (2016). Los diferentes tipos de responsabilidad social y sus implicaciones éticas. Ciencias sociales y políticas. 2, (3), 117-126. 
Castillo, C., Osuna, M., y López, G., (2012). Percepción y actitudes del residente acerca del impacto del turismo en la isla de Santiago (Cabo Verde). Revista de Investigación en Turismo y Desarrollo Local, 5, 1-23. Recuperado de http://www.eumed.net/rev/turydes/12/csg.pdf

Castillo-Pavón, O., Méndez-Ramírez, J., (2017). Los desarrollos turísticos y sus efectos medioambientales en la Riviera Maya, 1980-2015. Quivera, Revista de Estudios Territoriales. 19 (2), 101-118.

Celaya. (2015). Contexto Económico- Social. Cuenta Pública. Recuperado de http://celaya.gob.mx/cly/images/consultas/tesoreria/InformacionFinanciera/enero/NOTADM. pdf

CEPAL. (2007). Comisión Económica para América Latina y el Caribe. Indicadores Económicos del Turismo. Recuperado de https://www.cepal.org/publicaciones/xml/3/33603/2008_06_ind_economicosturismos_vf.pdf

Cohen, E. (1982). "Jungle guides in Northen Thailand: The dynamics of a marginal occupational role". Sociology Review 30, (2), 234-266doi.org/10.1111/j.1467954X.1982.tb00756.x

CONAPO (2000). Situación actual de las y los jóvenes en México: diagnóstico sociodemográfico. Consejo Nacional de Población. Recuperado de http://www.conapo.gob.mx/en/CONAPO/Situacion_actual_de_las_y_los_jovenes_en_Mexico _Diagnostico_sociodemografico

CONCANACO y SERVYTUR (2017). Indicadores económicos por estados 2018. Indicadores de Guanajuato. Recuperado de http://www.concanaco.com.mx/documentos/indicadores-estados/Guanajuato.pdf

DATATUR (2016, Julio). Subsecretaría de Planeación y Política Turística. Estadística Turística Derivada de los Censos Económicos 2014. Recuperado de http://www.datatur.sectur.gob.mx/comite\%20de\%20estadisticas\%20del\%20sector\%20turism o/censos_economicos_2014.pdf

Deloitte (2012, julio). La Responsabilidad Social y el Gobierno Corporativo. Recuperado de https://www2.deloitte.com/mx/es/pages/risk/articles/responsabilidad-social-gobcorp.html

Emmerich, G., (2004). Transparencia, rendición de cuentas, Responsabilidad Gubernamental y participación ciudadana. Polis: Investigación y Análisis Sociopolítico y Psicosocial. 2, (4), $67-90$ 
FIIAPP.(2011). Manual de Gestión Pública Responsable. Fundación Internacional y para Iberoamérica de Administración y Políticas. Recuperado de http://www.conr.es/descargas/FIIAPP_manual_GPR.pdf

Gujarati, D. (2004). Econometría. (4ta ed.). México, D.F: Mc. Graw-Hill

Gursoy, D., Jurowski C., y Uysal, M. (2002). "Resident attitudes: A Structural Modeling Approach". Annals of Tourism Research, 29, 79-105. Doi.org/10.1016/S01607383(01)00028-7

Guzman, A., y Fernández, G. (1997). El turismo desde la geografía. Revista bibliográfica de geografía y ciencias sociales. 7, (365), 742-798.Recuperado de http://www.ub.edu/geocrit/b3w-365.htm

Hincapié, G. (2013). Jóvenes frente a la Responsabilidad Social, la Comunicación y la Participación. Caso: Integración Subregional Centro Sur de Caldas.Recuperado de http://ridum.umanizales.edu.co:8080/xmlui/handle/6789/932

INAFED. (2017). Municipios de México fortalezcamos nuestras acciones en favor de la población joven. Día Internacional de la Juventud. Instituto Nacional para el Federalismo y el Desarrollo Municipal. Recuperado de http://www.inegi.org.mx/est/contenidos/proyectos/cn/tur/default.aspx

INEGI. (2015). Encuesta Intercensal 2015. Instituto Nacional de Estadística y Geografía . Recuperado de http://www.beta.inegi.org.mx/proyectos/enchogares/especiales/intercensal/

INEGI. (2018). Glosasrio. Instituto Nacional de Estadística y Geografía. Recuperado de http://www.inegi.org.mx/est/contenidos/espanol/sistemas/cem07/texcom/glosario/glosario.ht

$\underline{\mathrm{m}}$

INEGI. (2018). Turismo. PIB y Cuentas Nacionales. Instituto Nacional de Estadística y Geografía. Recuperado de http://www.inegi.org.mx/est/contenidos/proyectos/cn/tur/default.aspx

INEGI. (2018).Anuario Estadístico y Geográfico de Quinata Roo 2016. Instituto Nacional de Estadística $\quad y \quad$ Geografía. Recuperado de http://internet.contenidos.inegi.org.mx/contenidos/Productos/prod_serv/contenidos/espanol/bv inegi/productos/nueva_estruc/anuarios_2016/702825084370.pdf 
ISO. (2010). ISO 26000, Responsabilidad Social. International Orgnization for Standardization. Recuperado de https://www.iso.org/files/live/sites/isoorg/files/archive/pdf/en/discovering_iso_26000-es.pdf

López, A., Ojeda, F., y Ríos, M.. (2016). La responsabilidad social empresarial desde la percepción del capital humano. Revista de Contabilidad - Spanish Accounting Review. 20 (1), 36-46. Doi.org/10.1016/j.rcsar.2016.01.001

Martínez, E., (2005) Errores frecuentes en la interpretación del coeficiente de determinación lineal. Anuario Jurídico y Económico Escurialense. 38, 315-332.

Méndez, E., y Ablan, N. (2012). El Municipio: destino local. Tres dimensiones y una función rectora. Provincia. 27 (1), 11-42. Recuperado de http://www.redalyc.org/articulo.oa?id=55526545004

Mendoza, M., Leal, S., (2010). Turismo en Playa del Carmen - México. Impactos socioculturales en la Colonia Colosio. Estudios y Perspectivas en Turismo. 19, (5), 850-865.

Monfort de Bedoya, A. (2011). Responsabilidad Social Empresarial (Corporativa) y Juventud. Propuesta de análisis de contenido a través de las memorias de sostenibilidad. Mediaciones Sociales. 9, (2), 73-108 DOI: 10.5209/rev_MESO.2011.n9.38011

Morales, J., (2017). El Estado y la Responsabilidad Social Empresarial. Recuperado de http://www3.gobiernodecanarias.org/medusa/ecoblog/jumormed/2013/05/17/el-estado-y-laresponsabilidad-social-empresarial/

Moreno, M., y Coromoto, M., (2010). Turismo y producto turístico. Evolución, conceptos, componentes y clasificación. Visión Gerencial. 1, (1) 135-158.

Naciones Unidas, (2008). Cuenta Satélite de Turismo: recomendaciones sobre el marco conceptual, $2008 . \quad$ Recuperado de https://unstats.un.org/unsd/publication/Seriesf/SeriesF_80rev1s.pdf

OMT. (2018). Turismo y Migración. Organismo Mundial de Turismo. Recuperado de http://ethics.unwto.org/es/content/turismo-y-migracion

Propin E., y Sánchez, A., (2007). Tipología de los destinos turísticos preferenciales en México. Cuadernos de Turismo. 19, 147-166. ISSN: 1139-7861.

Rodrigues, M., Feder, M., y Fratucci., A. (2015). Impactos percibidos del turismo: Un estudio comparativo con residentes y trabajadores del sector en Rio de Janeiro -Brasil. 


\begin{tabular}{llllllll}
\hline Estudios $y$ & perspectivas en turismo. & 24, & $114-134$. & Recuperado de
\end{tabular}
http://www.scielo.org.ar/pdf/eypt/v24n1/v24n1a07.pdf

Romo, P., (2016). En Guanajuato, clúster atrae más visitantes. Recuperado de https://www.eleconomista.com.mx/estados/En-Guanajuatocluster-atrae-mas-visitantes20160922-0110.html

Sáenz, L., Tamez, G. (2014). Métodos y técnicas cualitativas y cuantitativas aplicables a la investigación en ciencias sociales. México.,D.F: Tirant Humanidades

Sánchez-Fernández, M.D. \& Ríos-Manríquez, M. (2019). Gestión de la Responsabilidad Social en el Gobierno Municipal en el área de turismo. España: RENUTEG \& Universidade da Coruña \& Universidad de Guanajuato.

Secretaría de Economía. (2016). Responsabilidad Social Empresarial. Recuperado de https://www.gob.mx/se/articulos/responsabilidad-social-empresarial-32705

SECTUR. (2003). Planeación y gestión del desarrollo turístico municipal. Secretaría de Turismo. Recuperado de http://cedocvirtual.sectur.gob.mx/janium/Documentos/003162Pri0000.pdf

SECTUR. (2013). Estudio de competitividad turística del destino Riviera Maya. Secretaría de Turismo. Recuperado de http://www.sectur.gob.mx/wp-content/uploads/2015/02/PDF$\underline{\text { Riviera-Maya.pdf }}$

SECTUR. (2013). Plan Nacional de desarrollo 2013-2018. Gobierno de la República. Programa Sectorial de Turismo. Recuperado de http://www.cmic.org.mx/comisiones/Sectoriales/turismo/2015/DOC_VIG_2015/programa_tu rismo.pdf

SECTUR. (2014). Infraestructura para el Turismo. Secretaría de Turismo. Recuperado de http://www.sectur.gob.mx/blog-de-la-secretaria/2014/09/19/infraestructura-para-el-turismo/

SECTUR. (2018). Atlas turístico de México. Secretaría de Turismo. Recuperado de https://atlasturistico.sectur.gob.mx/AtlasTuristico/bienvenido.do

SECTUR. (2018). Turismo de reuniones, contribuye al crecimiento económico y es una inversión social: De la Madrid. Secretaría de Turismo. Recuperado de https://www.gob.mx/sectur/prensa/turismo-de-reuniones-contribuye-al-crecimientoeconomico-y-es-una-inversion-social-de-la-madrid?idiom=es-MX 
Sistema de Arte y Cultura Celaya. (2018). Talleres y Eventos. Recuperado de http://www.cultura-celaya.com.mx/index.php

Tamayo, A. (2016). La Responsabilidad Social en México. Responsabilidad Social Empresarial y Sustentabilidad. Recuperado de http://www.responsabilidadsocial.mx/laresponsabilidad-social-en-mexico/

UNWTO (2018). Entender el turismo: Glosario Básico. Organización Mundial del turismo. Recuperado de http://media.unwto.org/es/content/entender-el-turismo-glosario-basico

Wooldridge, J., (2010). Introducción a la econometría.Un enfoque moderno. (4a. ed). ISBN13: $978-607-481-312-8$

Xacur, J., (2001). El Estado de Quintana Roo (2da ed). Q. Roo, México: Nueva Guía

Zárate, L.,( 2015). Lidera ciudad turismo de negocios en el país. Recuperado de https://www.am.com.mx/celaya/local/lidera-ciudad-turismo-de-negocios-en-el-pais$\underline{189488 . h t m l}$ 